\title{
Direct Digital Manufacturing Course into Mechanical Engineering Technol- ogy Curriculum
}

\section{Dr. Ananda Mani Paudel, Metropolitan State University of Denver}

Ananda Mani Paudel is Assistant Professor of Engineering at the Metropolitan State University of Denver. He was formerly on the faculty at the University of Wisconsin-Platteville. He has a B.S in mechanical engineering from Tribhuvan University, Nepal, an M.S. in Mechatronics from Gwangju Institute of Science and Technology, South Korea, and a Ph.D. in industrial engineering from Western Michigan University.

\section{Dr. Devi Kiran Kalla, Metropolitan State University of Denver}

Devi K. Kalla received a Ph.D. in industrial engineering from Wichita State University in 2008. He is currently an Associate Professor in the Department of Mechanical Engineering Technology at Metropolitan State University of Denver. He has a strong experience on composite manufacturing, machining, and modeling. His research interests include environmentally conscious manufacturing, green manufacturing/sustainable engineering, energy efficient manufacturing processes, and automated design and product development. 


\title{
Direct Digital Manufacturing Course into Mechanical Engineering Technology Curriculum
}

\begin{abstract}
Direct digital manufacturing (DDM) is a newer trend in advanced manufacturing. A CAD model could be converted into a physical product seamlessly with minimal human intervention. Additive manufacturing (AM) is a major constituent of DDM. Solid Modeling, G-code and 3D printing are the major steps in AM. AM technology that nests design and manufacturing tasks together offers many benefits but also suffers some constraints. Product design principles of AM are evolving; traditional design approach of "design for cost" and "design for manufacturing" might be relevant to AM, but not sufficient enough to live up to the new capabilities of AM.
\end{abstract}

AM education is essential to support its evolution and widespread adoption. Technological aspect of 3D printing is incorporated in a DDM course offered in the Mechanical Engineering Technology Program. This new course enables students to learn the theoretical aspects as well as help them understand the technological impact of DDM to the manufacturing industry. This course prepares them to deal with the newer developments and face upcoming challenges whether they will be pursuing engineering careers of product designer, 3D printing professionals. In this course students gain hands on experience in AM processes, product designing, 3D printing, and were able to analyze the technology by using product life cycle approach.

This newly developed course is successful in attracting a significant number of students. The course helps us to serve the advanced manufacturing community by preparing engineers, who are better equipped with the latest knowledge and skills. The outcome of this paper might be of relevance to anyone planning to offer similar courses in their institutions. The authors believe that this course will be a foundational one for developing future courses relevant to the field of DDM.

Introduction

Conversion of the computer aided design (CAD) model directly into a physical object is becoming a mainstream technological innovation in manufacturing, which has seen an exponential growth in recent years ${ }^{1}$. This advancement is creating a renaissance of United States (US) manufacturing, and some people even called it a new industrial revolution ${ }^{2}$. A consensus is building in the support of aforementioned perception and this agreement recognized DDM as the next technological trend to develop novel products and processes ${ }^{3}$.

AM has been used in industry, academic and consumer alike. Creating components using AM techniques is going beyond prototyping - in many industries it has already begun to be a reasonable part of manufacturing capacity. Its application is visible in medical, defense, and aerospace industries. On the consumer level also the technology is getting good traction. A Makerspace type of facility creates "citizen designers" - who can design and build their product with ease by using $\mathrm{CAD}$ and 3D printers, drawing attention of larger population, and have made "3D Printing" a fancy buzz word. It is proven that DDM technology has a potential 
and AM has moved it to a new height - creating things by putting materials layer by layer, wherever one needs. However, from an engineer's perspective, this technology is much more than creating some fun plastics items in your garage. To make the technology a viable option, an improvement in reliability of the technology and quality of the products is imminent. To ensure this improvement there is an immediate need of a skilled workforce with greater technical expertise and skill who can drive the technology and ensure its full benefit. To meet the workforce need, various institutions have put their effort in developing and offering curriculum and courses in varying formats at different levels and have experimented with various modes and methods of instruction.

Some have developed courses for general public to facilitate the AM education engagement and outreach $^{4}$. Others have introduced AM technology to high school students or teachers. For example, Research Experience for Teachers (RET) has trained high school teachers using the analytical and experimental methods as a short course. It provided them an opportunity to understand the technology better by allowing them to examine operational factors and impacts of the respective factors into the print time ${ }^{5}$. A methodology to use $3 \mathrm{D}$ printing as a tool for lab instruction in the machine design course is also presented ${ }^{6}$. AM content is also integrated as a part of project based learning such as design and fabrication of electric go-kart parts ${ }^{7}$, designanalyze-build-test project that uses AM to supplement instruction in finite element analysis ${ }^{8}$, or to model rocketry to enhance learning in undergraduate engineering design projects ${ }^{9}$. An interdisciplinary approach of designing and developing of a 3D printer machine, by integrating the knowledge of CAD/computer aided manufacturing (CAM), and automation methods acquired in other courses ${ }^{10}$ enable deeper learning. A few institutions are offering courses in a more traditional format into their engineering programs. For example, Austin Peay State University has offered a concentration in their undergraduate manufacturing curriculum ${ }^{11}$. Ohio Northern University developed a curriculum on digital manufacturing and simulation ${ }^{12}$. Courses such as Additive Manufacturing: Theory and Practice (ME 599) was offered at the University of Michigan at Ann Arbor with more focus on the technical side at the graduate level. All these and other efforts are helping to fill the gap.

However, a more focused effort such as "teaching factory" — providing AM education in a medical school format ${ }^{13}$ is needed to meet the educational need of the exponentially growing field. The authors agree with approach of "teaching factory" - systematic interactions between professionals and students working on a real life industry problem using system approach, same way as medical students are trained in hospitals during their study. In an attempt to realize the teaching factory model, a more hands on course that encompasses both theoretical competency as well as practical considerations in solving real life problems is developed and offered.

This paper presents a more comprehensive course devoted to AM, covering aspects of the technology as well as integration of the existing technology and its management. For example, 1) modeling section constitutes basic CAD and 3D scanning; 2) enabling technology sections cover topics in AM technologies and materials; 3) impact analysis section includes production systems, environment and safety relevant to AM. Design for AM considers the shape and dimension based on the functional requirements and loading conditions rather than shape and size of the stock material. Different open source and proprietary AM technologies with the capability of printing plastics and metal are incorporated. Basic finite element analysis (FEA) of 
the CAD model is used to study stress and deflection of the designs. Topics in production approach and integration of 3D printers into the existing production system are also covered and presented to the students.

The course is delivered into lecture, lab and semester project/research format, which provide students an opportunity to learn existing theories. They practice with different tools and techniques available. The class is also required to perform research in improving the systems or creating newer tools and techniques. The course was developed and offered based on the demand of our industry partners, and is supported by both industry and a Federal Grant.

The course was designed by utilizing the Universal Design for Learning (UDL) ${ }^{14}$ approach; both subjective and formative assessment are performed to evaluate the student's learning outcome. Lectures are reinforced by the case studies and in class discussion. Concepts are elaborated with an aid of pictures, videos and diagrams on the white board. In addition to the students' participation in the lab work, various physical samples are presented to broaden their understanding. An individual and group lab report is required to summarize procedures, observation, and analysis after completion of each lab. Homework (HW) with different types of problems are presented based on the lecture and reading materials. Individual feedback to a specific student as well as feedback to the group(s) are provided in case a trend in the mistake or common misunderstanding is noticed in the students' work.

During the tests, multiple choice, multiple answers, true/false, essay type, and numerical type questions are asked. Students are encouraged to use sketches and diagrams to elaborate their response. Quizzes are administered both on computer and paper. An online tool such as Socrative $^{15}$, is used to perform formative assessment at different points throughout the semester. In addition to lab, HW, quizzes and exams, a project and research component is also built in to assure students that the field is emerging and it is critical to stay current. These assessments are used for both formative and summative purpose. The final exam is used as a summative assessment. For the outcome assessment pre- and post-surveys are performed asking students about their understanding in DDM, their expectations of the course and interest areas. Most of the students possess some familiarity with 3D printing - mostly fused deposition modelling (FDM). There was a wide range of interest among the students such as gaining operational command to specific machines, design for additive manufacturing (DFAM), production systems, quality control, etc. Open source consumer 3D printers are abundantly available enabling people in realizing their idea from a concept to a physical model. However, to make the physical model within form, fit and function, there is a greater need of technical understanding.

\section{About the Program}

Mechanical Engineering Technology (MET) Program is housed within the Engineering \& Engineering Technology Department, which is under the College of Professional Studies at Metropolitan State University of Denver. MET program offers two concentrations: mechanical and manufacturing. The program has grown three times since 2009. Our students enjoy hands on component of the program, which is also highly valued by the industry. We offer calculus based courses and most of our students also minor in mathematics. 


\section{Course Introduction}

DDM is an approach of converting computer generated models into physical objects with minimal human interference. Ideally, a product that is designed and analyzed could be manufactured seamlessly either using subtractive or additive manufacturing techniques automatically. Increased processing, storage and graphics capability in computer technologies has enhanced the capabilities of CAD/CAM applications. CAD applications have better ability to incorporate complex geometrics to generate high quality solid models with shape and features almost in parity with real life physical model. Advance manufacturing is becoming broader and new courses are developed to train the future workforce. This course in DDM focuses more on $\mathrm{AM}$ although concepts of computer numerical control (CNC) programming for subtractive manufacturing are also introduced at the beginning of the semester. Topics in a 3D scanning, PLM and production systems make it much broader than just 3D printing course. However, the main thrust of the course is to offer introductory content on various AM technologies, process parameters, and hands on activities. The three credit hour course is developed in an integrated lecture and lab format. The course is offered as an elective course in undergraduate upper class level (juniors and seniors) with only one pre-requisite - solid modelling (CAD course). This allowed students from other departments to take the course. In fall 2015, 21 students registered into the two sections of the course. We are trying to make it a regular course by offering it every semester, which will allow us to provide rigorous content both in depth and breadth on a continuous basis. A standard departmental instructional requirement is satisfied, which is stated in the course description as:

This is a cross disciplinary lecture/lab course that explores the latest applications of DDM and digital 3D scanning. Through this course, students are introduced to current developments and the critical challenges of 3D printing technologies. Emphasis is placed on practical experience in utilizing departmental equipment to produce digital 3D CAD files and output them in a suitable format appropriate to be used by DDM equipment. Students will apply knowledge of 3D scanning for reverse engineering purposes and utilize the information to recreate the physical object using additive manufacturing techniques. The goal of the course is to foster DDM and promote the understanding of AM technology, process parameters and capabilities.

The objective of the course is listed as follows:

- Create the design of an object suitable for additive manufacturing processes

- Evaluate and select appropriate 3D manufacturing technologies for specific applications

- Demonstrate proficiency in the use of additive manufacturing and 3D scanning technologies

- Effectively format and transfer digital files to 3D manufacturing equipment

- Analyze the strengths and weaknesses of different 3D manufacturing techniques.

The objectives follow the new Bloom's Triangle ${ }^{16}$, starting from lower level-memorizing process steps and parameters to the highest level of cognitive domain of understanding (complex 3D technology), applying skills (modeling, file formatting, machine set ups), analyzing (geometric features of the CAD model vs. Physical model) and creating (summarize the capabilities of the 3D printing and ability to select proper AM technology to create parts based on product geometry and material requirements). 
Course introduction is started by asking students their familiarity on AM and their expectation of the class. It was identified that students of different levels and background were attending the class. The class constitutes students from industrial design, mechanical and manufacturing concentration taking this course during their sophomore to senior years. Few of the students had previous working experiences in 3D printing. The variety of expectations are listed 1) able to start the business, 2) interested in sustainability aspect of 3D printing, 3) process control and quality of the products, 4) materials and equipment, 5) design for AM, etc. The syllabus was slightly modified to support and maintain their aspirations. However, the scope of the course, and its four core components remained same, which are: fundamentals of $\mathrm{CNC}$, basic AM processes and technologies, solid modeling \& 3D scanning, and applications of AM.

1. Concept of $\mathrm{CNC}$ was introduced to lay down the foundation and its relevance to $3 \mathrm{D}$ printing. Since 3D printing is the expansion of $\mathrm{CNC}$, the 3D printers use the G- and $\mathrm{M}$ codes, which was originally developed for CNC machining.

2. In reference to varieties of AM technologies available in the market, basic operating principles, materials, printer set up, pre- and post-processing of the following technologies were covered.

a. Stereolithography (SLA) process involves curing or solidifying a photosensitive polymer resin in a vet by light beam (ultraviolet laser). The 3D model is built up layer by layer as the cured layer in the bed recedes down into the vet and new resin covers the previously cured layer. The resin covering the previous layer can now be cured by the ultraviolet laser to the previous layer, thus building the next layer of the part. Only the liquid polymers could be used in this process, and the product's surface finish is better.

b. In FDM, a thin filament material extrudes on to a heated build plate in layers building the part from the bottom to the top. The nozzle of the printer is heated to the correct temperature to extrude a material at its melting point so that it can fuse with the previously printed material. The main materials used in this section were polycarbonate (PC), and acrylonitrile butadiene styrene (ABS). However, new materials such as nylon and carbon fiber were introduced theoretically. FDM printing is a low cost process. Nozzle size, layer thickness, etc. control the quality of the print in FDM.

c. Selective Laser Sintering (SLS) is very similar to Stereolithography except for the materials used and the heat needed to cure or solidify the materials. The process uses a carbon dioxide laser beam to sinter or fuse powder which resides in the powder bed. Materials with higher melting temperatures could be melted with a laser and bond together layer by layer in this process. However, the power requirement for the laser to reach higher temperatures is also very high, which imposes process complexity. Metal parts could be printed using this technology. Powder size plays a primary role to limit the surface finish and quality of the product. 
3. Tool path to control the movement of the printer head is generated from the CAD model. Parametric solid modelling and surface modelling are the basic CAD technologies. Solid modelling creates a model that has the filled volume. It closely represents a physical object by having data of physical properties such as mass, density, along with the geometric information. Surface modelling, on the other hand, generates the outlook of the objects as a surface model but doesn't reflect the physical properties as in a solid model.

Solid modelling is preferred over surface modelling in AM as it has simpler representation of geometric information and provides information that is useful to generate tool path.

4. 3D scanning technology enables reverse engineering of a physical part into a CAD model. Laser or light beam technology with a triangulation principle is used to capture the geometric coordinates of the points on the object; the point cloud so collected is then converted into a solid model. The solid model can be used as a CAD model for visualization or directly be used in AM to reproduce the object.

AM is growing in every sector of industry, applications are presented in aerospace, medical and auto industries. Case studies from different industries, safety and sustainability of the 3D printing are also included. Tentative schedule of the course is presented in Table 1.

Table 1. Tentative Schedule

\begin{tabular}{|c|c|c|}
\hline Class & Lecture Topic & Lab work \\
\hline 1 & Introduction to course, syllabus, manufacturing trends & Lab visit and safety \\
\hline 2 & 3D scanning technologies & 3D scanning lab \\
\hline 3 & $\begin{array}{l}\text { Solid modelling and CAD for DDM } \\
\text { Design tools, pre-processing, and strength criteria } \\
\text { Exploring design freedoms }\end{array}$ & Solid modelling refresher \\
\hline 4 & Direct Digital Manufacturing technologies: Stereolithography (SLA) & SLA lab \\
\hline 5,6 & $\begin{array}{l}\text { Direct Digital Manufacturing technologies } \\
\text { - Fused Deposition Modeling (FDM) } \\
\text { - Parameters: quality, resolution, slicing, speed, time }\end{array}$ & SLA lab \\
\hline 7,8 & Selective Laser Sintering (SLS) & FDM lab \\
\hline 9 & Midterm - I & FDM lab \\
\hline 10 & $\begin{array}{cl}\text { Materials for DDM } \\
\text { - } \\
\text { - } & \text { Liquid Polymer Systems } \\
\text { - } & \text { Molten Material Systems } \\
\text { - } & \text { Solid Sheet Systems }\end{array}$ & FDM lab \\
\hline 11 & Commercial AM Machines & Metal Printer lab \\
\hline 12 & $\begin{array}{l}\text { Post-processing in DDM: surface texture improvement, property } \\
\text { enhancement }\end{array}$ & Metal Printer lab \\
\hline 13 & 3D Printing, safety and sustainability, other features/ benefits & Projects \\
\hline 14 & Current and Future Applications & Projects \\
\hline 15 & Project Presentation /course Evaluation & \\
\hline 16 & Final Exam & \\
\hline
\end{tabular}

Descriptions of Lab and Homework 
Laboratory content of the course is aligned with lecture. Works in the lab are designed to supplement the lecture and reinforce key practical concepts.

Lab 1: File Conversion, Formatting \& Mesh Manipulation

A digital data file of virtual model is critical to DDM, as it is the main input from which all aspects of the manufacturing process are derived. The primary objective of this lab is to understand different CAD file formats, convert part data between common file formats, and investigate mesh information and metrics. Students analyze mesh data for potential problems and perform mesh manipulation for both repair and simplification purposes. A CAD solid model is provided to the students with procedure to perform the above-mentioned tasks. This is an individual lab work.

\section{Lab 2: Print Variables in AM}

There are a large number of variables available in AM that can impact quality and mechanical properties of the manufactured parts. Students are provided with CAD model and asked to experiment with variables such as: infill percentage, patterns, layer height, etc. The printed specimen is required to be tested for tensile strength, and students are required to report the findings. Open source software such as MeshLab and Slic3r are used in addition to other 3D printer proprietary software from uPrint and Prox100. MeshLab is used for checking nonmanifold and open holes in the model; Slic3r is used to generate G-code.

\section{Lab 3: Design for Additive Manufacturing (DFAM): Fused Thermoplastics}

FDM requires specific design considerations. The objective of this lab is to educate students on the technical side of fused thermoplastic printing and provide an opportunity to design, fabricate and evaluate fused thermoplastic parts. Students are asked to design an object that must fit within a given volume. They need to be able to save files in different formats (CAD, Mesh, slice, G-code) and perform printer set up.

Lab 4: DFAM: Stereolithography (SLA)

The objective of this lab is to educate students on the technical side of stereolithography and provide an opportunity to design, fabricate and evaluate SLA manufactured parts. Prior to any design activities, all students will receive instruction on the technical process of stereolithography, to include all design fundamentals necessary to produce manufactural parts via SLA processes. As group work, students are to design a single object with a specified intent that must fit within a given volume. Students need to compare the properties of the physical model to that of the CAD model. A comparative study between FDM and SLA is also required as a part of this lab.

Lab 5 DFAM: Powder Bed Fusion (PDF) \& Direct Metal Printing (DMP) The objective of this lab is to educate students on the technical side of powder bed fusion as it applies to direct metal printing (DMP) and to provide an opportunity to design, fabricate and evaluate metal parts. Instruction is provided on the technical process of powder bed fusion and direct metal printing including all design fundamentals necessary to produce manufacturable parts via the DMP process. Students design a model in CAD that must fit within a given volume. Additionally, the object must have a displacement of no more than specified by the manufacture when printed. The part dimensions and an estimated mass will be recorded. 
Unlike thermoplastic printing, DMP requires all variable definitions to be part of the original CAD file. Parts must be designed appropriately for the DMP process to fit within the size and displacement requirements and still fulfill their design intent. The file must be converted into a mesh, verified as watertight and be of good quality. Upon finalization of the design, all digital files must be submitted electronically. This includes the original CAD file(s) and any supporting design files regardless of format. After fabrication the part will be visually inspected, photographed, weighed and dimensions recorded.

\section{Lab 6: 3D Scanning \& Reverse Engineering}

3D capture technology is an important facet of the AM ecosystem and presents many new problem-solving methodologies. The objective of this lab is to educate students on available 3D scanning technologies and provide hands-on experience with different scanning technologies. Students need to scan an object and create a CAD model or .stl file, which they need to print using FDM.

The 3D printers used in this course were: Rostock MAX V2, uPrint SE from stratasys for FDM, DropLit SLA, and Prox 100 metal 3D Printer, which are shown in Figure 1.

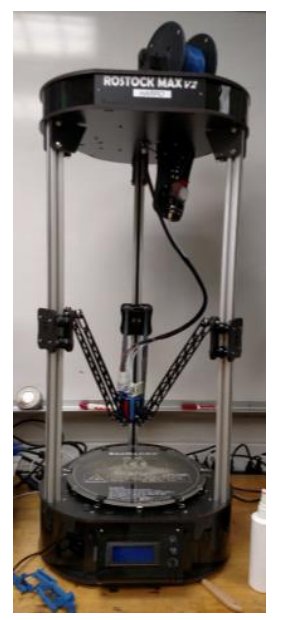

a) Rostock MAX V2 b) uPrint SE

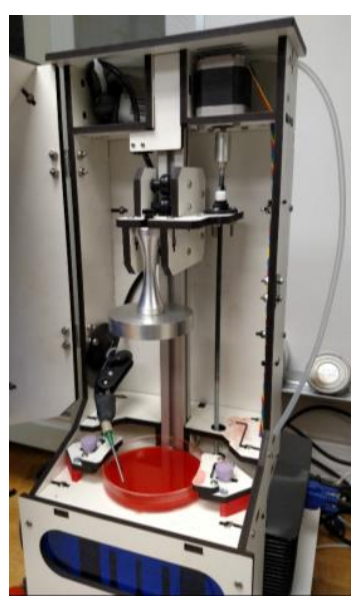

c) DropLit SLA

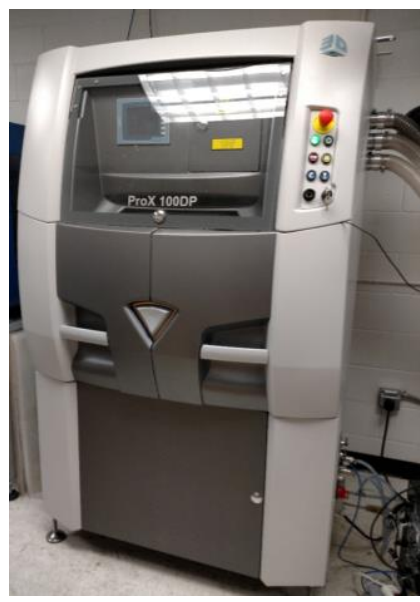

d) Prox100 metal 3D Printer

Figure 1. 3D Printers used in the course

Individual homework is devoted to each core areas of the course as follows:

HW 1: Draw tool path and write G-code to drill the holes and to mill the sides for a given part HW 2: Conceptual questions regarding file formats, printer parameters, techniques in DFAM HW 3: Critique a given manufacturing process/steps that are being used to manufacture a given part, perform stress and deflection analysis, and modify the design for AM

HW 4: Conceptual questions on SLS and printer set up, design support structures

HW 5: Present a case study by using a scanned CAD model and comment on the features available, possibility of features modifications, etc. 
HW 6: Explain how AM contribute to Product Life Cycle management based on a case study provided

HW 7: Safety in AM and explain the contributions of AM in sustainability, with specific examples

\section{Assessment Policy}

Students' knowledge of the course material must be demonstrated through homework, projects, quizzes, labs and exams. The distribution of the grade is shown in Table 2.

Table 2 Assessment and Grading Policy

\begin{tabular}{|l|c|}
\hline Midterm Exam: $15 \%$ & Letter Grades: \\
Course Project: $15 \%$ & $\mathrm{~A}=90-100 \%$ \\
Final Exam: $15 \%$ & $\mathrm{~B}=80-89 \%$ \\
Homework: $15 \%$ & $\mathrm{C}=70-79 \%$ \\
Quizzes: $10 \%$ & $\mathrm{D}=60-69 \%$ \\
Research Paper: $15 \%$ & $\mathrm{~F}=0-59 \%$ \\
Lab Exercises: $15 \%$ & \\
\hline
\end{tabular}

\section{Learning Outcome}

Based on the objectives and assessment policy as mentioned earlier, students' learning was measured at varying levels at different points of time using a mix of methodologies. These assessments were designed in an attempt to measure students' lower- and higher- level thinking of course content. The number of quizzes and homework were developed covering each aspect of the course content and are assigned after lecture and lab session. Based on the scope and nature of problems these assignments vary between individual and group activities. HW 1, 2, 4, and 5 are individual to ensure students understand the basics whereas HW 3, 6 and 7 are assigned to a group of two students to foster collaboration and have discussion to engage them in higher level learning. With the same approach, Lab 1 and 2 are assigned as individual and the remaining are assigned in a group of 3-5 students. The larger group is required due to the longer printing time and limited number of 3D printers available for different technologies.

Homework, quizzes and exams are administered in different modes and formats. Online and/or in class submission is allowed considering the fact that some of the files are required to be transmitted electronically, and a hard copy for summary report. Format of the assessment consists of problems for short answer, multiple choice, true/false, fill in the blank and essay type questions. Individual project and research topic were selected by the students based on their interest and familiarity. The instructor encourages the students to pick the same project and research topics due to the limited time available and scope of the section within the course. There are a few who chose differently. Topics range from 1) use of AM in space, 2) drug production, 3) consumer products, 4) 3D scanning technologies, 5) design tool for topology optimization and AM, 6) making assembled products using 3D printing, 7) sustainability and recycling technology for parts created in FDM, etc. Separate guidelines are provided for the research paper and project report submission. Deliverable project work consists of 3D printed parts and reports, whereas an academic style paper is required for the theoretical research projects on a topic for 
which a resource is not available to produce the physical item on campus. For outcome assessment, students are asked the following questions at the beginning (pre-) and at the end (post-) of the semester. A Likert scale is used to capture the students' learning outcome. In 1-5 Likert scale, 5 is very good grasp on the topic and 1 is don't know at all. The outcome evaluation is shown in Figure 2.

- What is $3 \mathrm{D}$ printing?

- What is 3D scanning?

- Type of AM technologies available?

- Kind of shapes and geometry AM can produce?

- Design a product for AM?

- Factors in AM?

- Overall confidence in using AM?

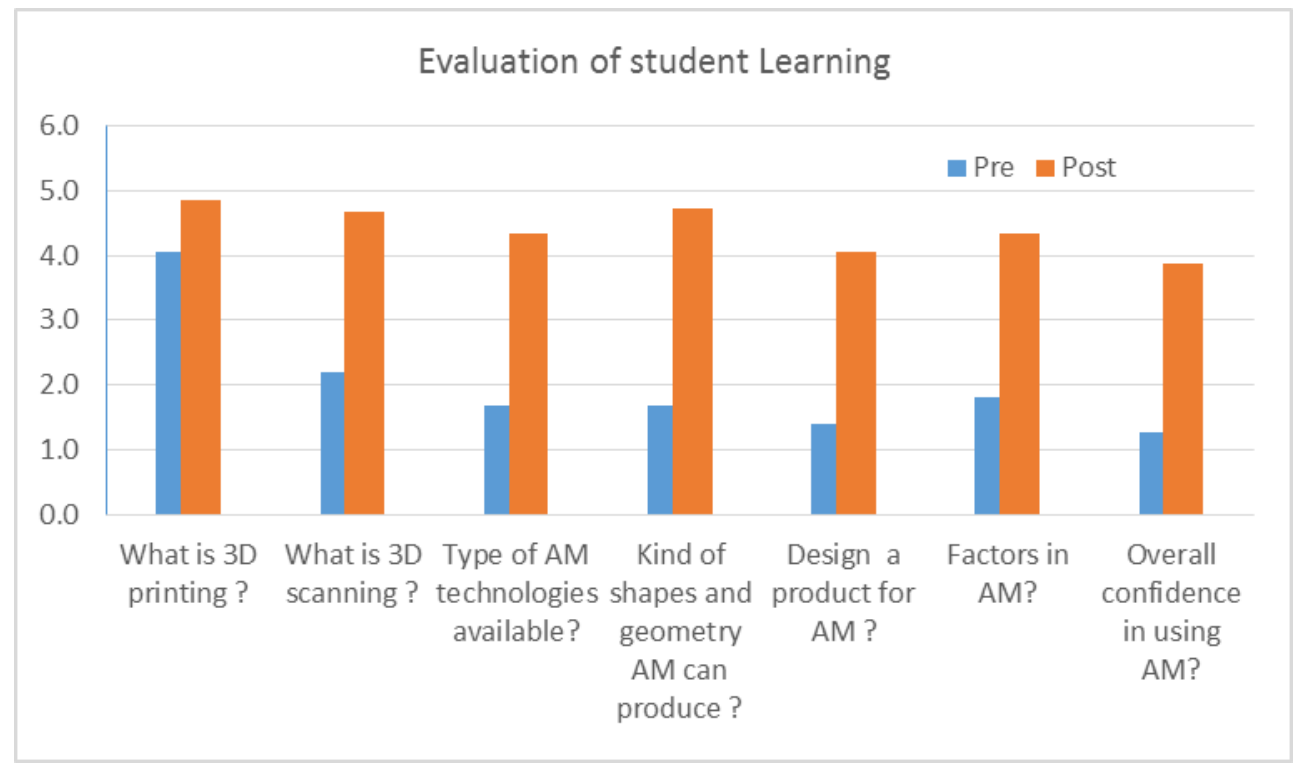

Figure 2 Student's learning outcome

It is clear that most of the students have heard of 3D printing, but very few are familiar with the word "additive manufacturing" that we commonly use in engineering as opposed to the common consumer buzz word "3D printers." Those students who were familiar with the technology and had some experience working with FDM Printers possess some technical knowledge, which was mostly limited within the FDM technology. Students have either very high expectations (excitement) or are skeptical to the viability of the technology. Some of the students also expressed their doubt regarding the applicability of AM to make functional load bearing components. The limited precision of 3D printed parts would not be useful for assembly needing components having mating surfaces for dynamic systems. After the completion of the course they realize the benefits and constraints, which is reflected during post- survey as shown in Figure 2. Students are able to create parts in CAD and convert that part into a physical model considering respective technologies, process steps, parameters and materials. They acquire a broad understanding of the different $\mathrm{AM}$ technologies and perform various tests of 3D printed parts for functional use. Students did well in this course, as the grade distribution shown in Figure 3 suggests. 


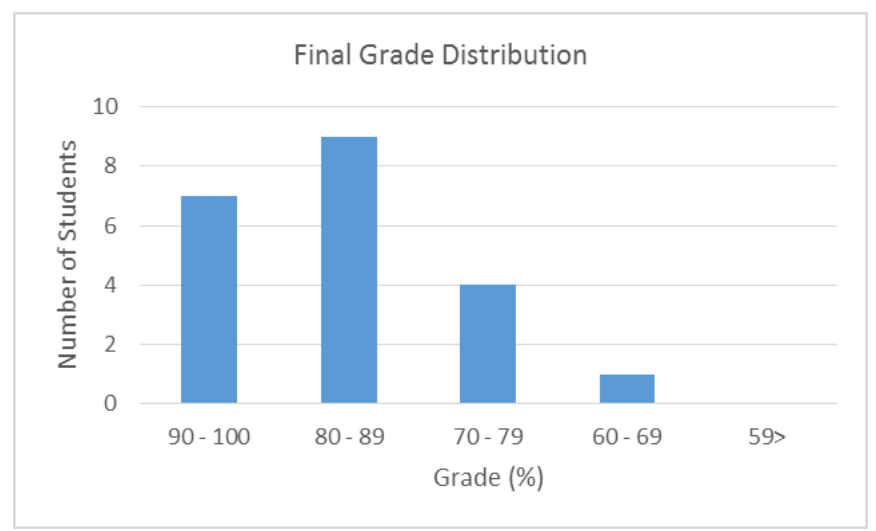

Figure 3 Student's Final Grade Distribution

The majority of students scored $80 \%$ or more (letter grade B). One student who missed the class for a couple of weeks towards the end of semester was not able to cover the content that he missed received the lowest grade.

The students' work involved designing and 3D printing individual parts as well as complete assembly as shown in Figures 4-5. Different types of geometry and complexities were studied. Printing a complete assembly in a single run involved greater planning in the design phase including adjusting tolerance as per the printer parameters, removing fill material, part orientation, etc. Different types of materials including metal were used in 3D printing.

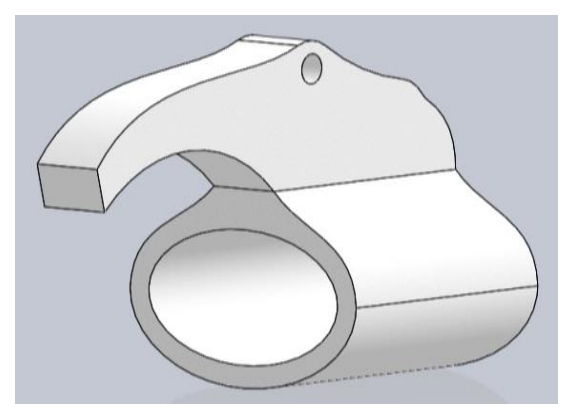

a) Multipurpose keychain CAD and 3D Printed
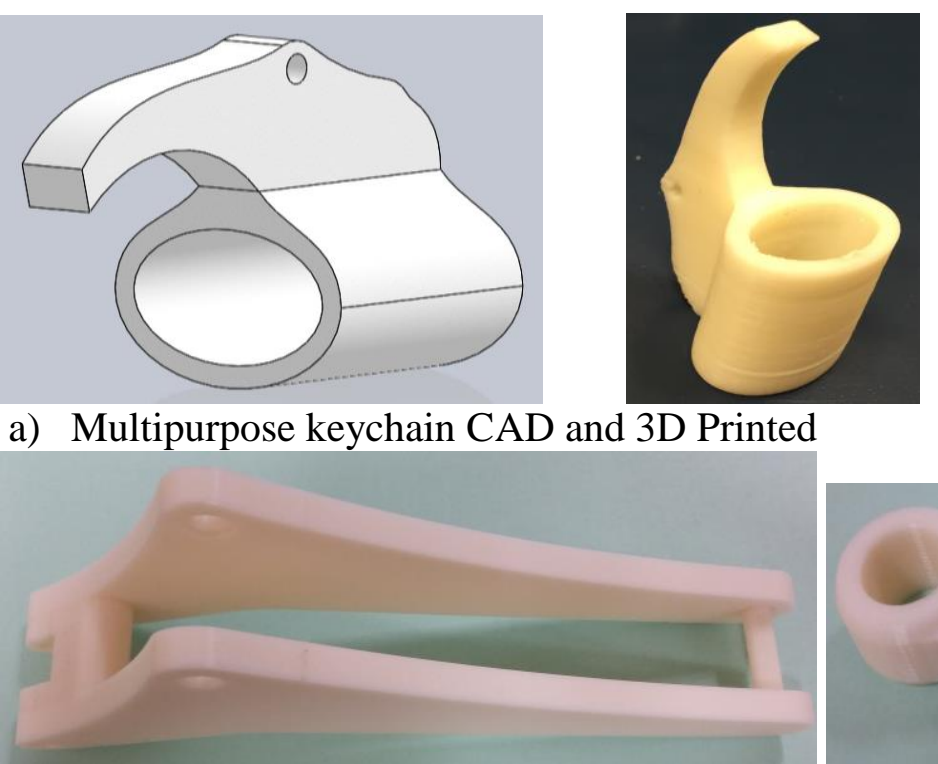

c) Aircraft's door hinge

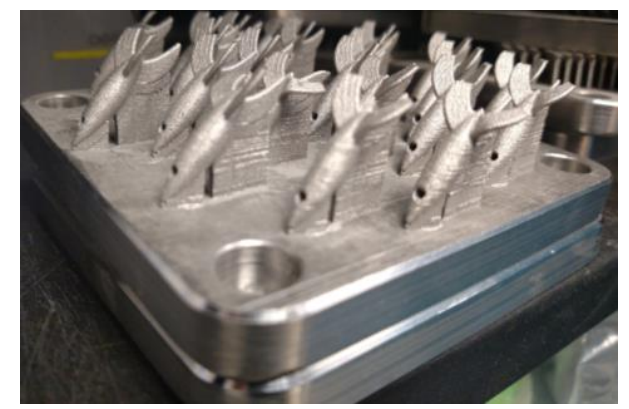

b) Array of fish like shapes

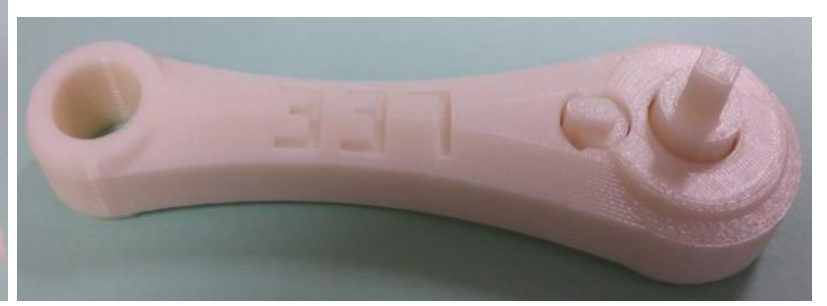

d) Ratchet

Figure 4. Plastics and metal 3D printed parts 


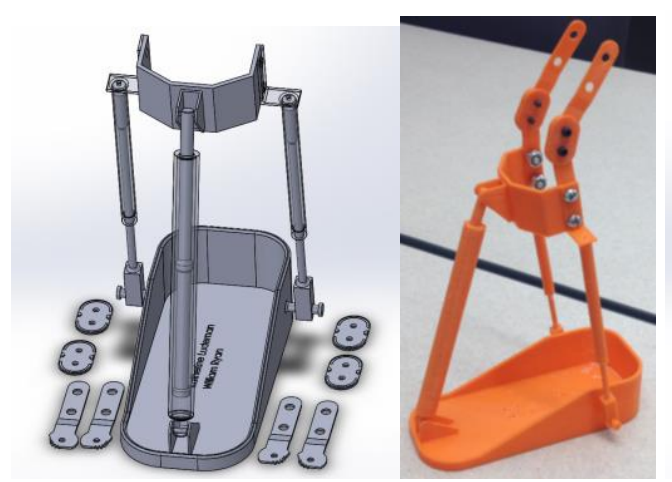

a) Adjustable foot holder
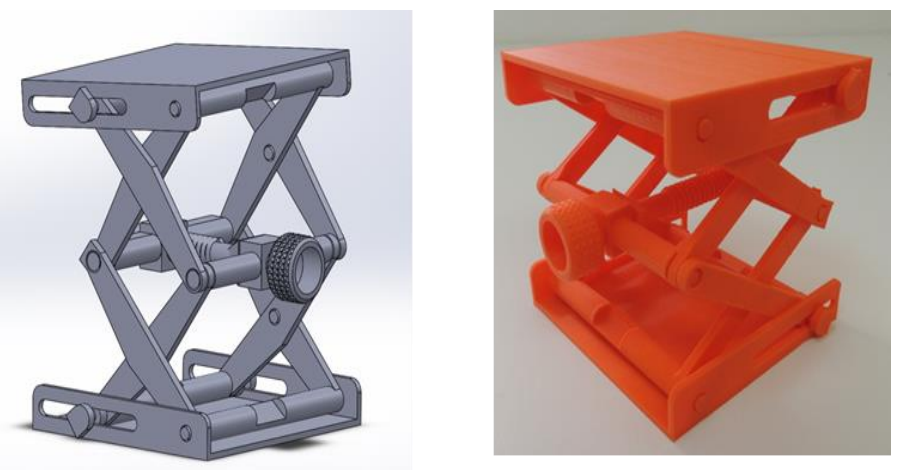

b) Screw chain lift

Figure 5. Sample of Student's work- assembly direct from 3D printer

As shown in Figure 4-5, individual parts as well as complete assembly are designed and made by the students. The objects have different design criteria and expectations. 4(a) is an example of compilation of multiple parts into one, and 4(c) is designed to minimize the number of parts of an existing design. 4(d) has enclosed gearing and locking mechanism designed within a given tolerance to achieve a functional low torque ratchet. 5(b) is an application of 3D printed plastics thread, which is the critical component in a screw chain lift.

\section{Conclusion}

In conclusion, the DDM course has been successfully developed and is offered using the latest technology and resources. Three main AM technologies are included namely: SLA, FDM and DMP that effectively incorporate plastics and metal - the common materials used in AM. Features of these technologies and their benefits as well as limitations are explained in greater detail. Case studies pertaining the impact of AM to the manufacturing as well as evolving methodology to use AM in different modes and formats (prototype, parts, assembly) are included.

Students are engaged with AM, which requires different mindset and technical know-how from the very beginning of product design and development, and doesn't complete until the product life is over. The course is developed using UDL, which also encompasses the ABET criteria, use of different modes of instruction including hands-on to make it more engaging.

During the course the authors realized that this course should now be offered to all engineering majors as product development and manufacturing is advancing towards AM. A growing number of manufacturing and product design companies are heading to incorporate AM into their business model.

\section{Limitations and Scope of Future Improvement}

Logistics and time management are critical to stay within the weekly schedule, as 3D printing takes a longer time than the regular class time. No reasonable printing can be accomplished within the allocated time. It is imperative that parts need to be fabricated outside of scheduled lab time. Although the 3D printers are easy to set up and run, the authors believe a continuous supervision of the lab is essential to stay on schedule. AM is a relatively new field, and there are 
not many textbooks available, the one that is being used in this course is a good reference book rather than a textbook. The main benefits of AM is design flexibility, and shape complexity, which are yet to be explored in a greater detail.

\section{Acknowledgement}

The authors are grateful to William Carver, our lab coordinator who contributed in developing the labs, and played a greater role in lab instruction as well as provided practical insights in designing and setting up 3D printers. We also appreciate our students' diligent work and their willingness to be available outside the class time.

\section{References}

[1] Wohlers Associates. Wohlers Report 2015, "3D Printing and Additive Manufacturing State of The Industry". Annual Worldwide Progress Report. Fort Collins, CO. 2015

[2] Berman, B. "3-D Printing: The New Industrial Revolution". Business Horizons 55(2), P. 155-162, 2012. Http://Www.Sciencedirect.Com/Science/Article/Pii/S0007681311001790

[3] Tzu-Liang Bill, T.; Richard, C.; Radian, G. B. "Fusing Rapid Manufacturing With 3-D Virtual Facility and Cyber Tutor System into Engineering Education". Proceedings of the 2014 ASEE Annual Conference and Exposition. Indianapolis, Indiana

[4] Ranjeet, A.; Robert, A. C. "Facilitating Additive Manufacturing Engagement and Outreach". Proceedings of the 2015 ASEE Annual Conference and Exposition. Seattle, Washington.

[5] Lisa Denny, C. et al. "RET Project in Additive Manufacturing. Proceedings of the 2011 ASEE Annual Conference and Exposition. Vancouver, British Columbia.

[6] Ananda M, P. "Realizing Proof of Concept in Machine Design with 3d Printing". Proceedings of the 2015 ASEE Annual Conference and Exposition. Seattle, Washington.

[7] Kee, M. P."Design and Fabrication of an Electric Go-Kart Using 3D Printing". Proceedings of the 2015 ASEE Annual Conference and Exposition. Seattle, Washington.

[8] William, E. H.; Rick, W.; Sarah Christine, G. "Using Additive Manufacturing and Finite Element Analysis in a Design-Analyze-Build-Test Project". Proceedings of the 2015 ASEE Annual Conference and Exposition. Seattle, Washington.

[9] Sven, G. B.; Timothy, F. W.; Randall, G. B. "Maker: Applying 3D Printing to Model Rocketry to Enhance Learning in Undergraduate Engineering Design Projects". Proceedings of the 2015 ASEE Annual Conference and Exposition. Seattle, Washington.

[10] Yalcin, E. et al. "Interdisciplinary Senior Design Project to Develop a Teaching Tool: Dragon Conductive 3-D Printer". Proceedings of the 2014 ASEE Annual Conference and Exposition Indianapolis, Indiana.

[11] Chin-Zue, C.; Adel, S. "Expanding a Manufacturing Technology Curriculum to Include Additive Manufacturing". Proceedings of the 2011 ASEE Annual Conference and Exposition. Vancouver, British Columbia.

[12] Paul, N. "Digital Manufacturing and Simulation Curriculum". Proceedings of the 2008 ASEE Annual Conference and Exposition. Pittsburgh, Pennsylvania.

[13] Huang, Y. et al."Additive Manufacturing: Current State, Future Potential, Gaps and Needs, and Recommendations". Journal Of Manufacturing Science And Engineering, 137(1), 2015. Http://Dx.Doi.Org/10.1115/1.4028725

[14] "Components of UDL Curriculum" retrieved from http://www.udlcenter.org/aboutudl/udlcurriculum

[15] http://www.socrative.com

[16] Bloom's Taxonomy. Retrived form https://cft.vanderbilt.edu/guides-sub-pages/blooms-taxonomy/ 